\title{
Effect of Extractives on the Physicochemical Properties of Biomass Pellets: Comparison of Pellets from Extracted and Non-extracted Sycamore Leaves
}

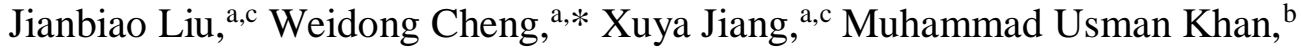 \\ Qingfa Zhang, ${ }^{\mathrm{a}, \mathrm{b}, \mathrm{c}}$ and Hongzhen Cai ${ }^{\mathrm{a}, \mathrm{c}}$
}

\begin{abstract}
Physicochemical properties of biomass pellets were compared following their preparation from extracted and non-extracted sycamore leaves. The goal was to achieve high-quality biomass pellets. Batches of pellets were prepared at different moisture contents and pressure. The properties, including pellet density, diametric compressive strength, and combustion performance, were analyzed. Pellets produced from extracted leaves had higher pellet density (between 1125 and $1250 \mathrm{~kg} \cdot \mathrm{m}^{-3}$ ) compared to those made from non-extracted leaves. In addition, data of the combustion experiment showed more weight loss in extracted leaves' pellets and a higher burning rate $\left(9.54 \% \cdot \mathrm{min}^{-1}\right)$ than that of non-extracted leaves' pellets $\left(8.47 \% \cdot \mathrm{min}^{-1}\right)$. Also, the pellets made from extracted leaves could be ignited and burned easily compared to non-extracted leaves. However, the diametric compressive strength was not always higher in extracted leaves' pellets compared to non-extracted. In general, it was concluded that extraction could increase the pellet density and improve combustion performance but did not fit the purpose to increase the diametric compressive strength. The analysis and conclusions can provide a reference for the production of high-quality biomass pellets.
\end{abstract}

Keywords: Biomass pellets; Sycamore leaves; Extractives; Moisture; Pressure; Physicochemical properties

Contact information: a: School of Agricultural Engineering and Food Science, Shandong University of Technology, Zibo 255000, China; b: Department of Biological Systems Engineering, Washington State University, Richland, WA, 99354, USA; c: Shandong Research Center of Engineering and Technology for Clean Energy, Zibo 255000, China; *Corresponding author: sdutCwd@163.com

\section{INTRODUCTION}

The gradually increasing global energy demands as well as increasing risks of climate change due to the continuous use of conventional fossil fuels has diverted the global interest towards cleaner renewable energy sources (Bajwa et al. 2018). Among all the energy sources, biomass is considered promising due to its large availability, renewable nature, and lower cost. Moreover, the emission of pollutants as well as the net carbon emission is quite low compared to conventional fossil fuels (Zhou et al. 2016). The carbon in biomass is the result of the absorption of carbon dioxide from the atmosphere during the photosynthesis process of plants. The carbon dioxide generated during the energy recovery process from biomass is recycled when new plants are grown. Hence, biomass is a carbon neutral source of energy (Saidur et al. 2011). Therefore, there is an urgent need to use efficient, renewable energy technologies to recover energy from biomass to diminish the use of conventional fossil fuels, reduce the risks of climate change due to the emission of greenhouse gases, as well as to ensure the energy security. 
The estimated global energy potential of forest and agricultural residues is approximately $30 \mathrm{EJ} \cdot \mathrm{yr}^{-1}$ compared to the total energy demand, which is approximately $400 \mathrm{EJ} \cdot \mathrm{yr}^{-1}$ (McKendry 2002). It has been observed that due to the continuously increasing use of biomass as a renewable energy source, about half of the energy consumption of the world will be met by using biomass in 2050 (McKendry 2002). China is an agricultural country and large amounts of biomass are produced by different agricultural activities, which equals to 460 million tons of standard coal. However, currently only a small portion of this abundantly available biomass is used for energy production by utilizing different conventional and inefficient biomass conversion technologies. The increased use of these conventional inefficient biomass conversion technologies not only causes the loss of energy due to their lower efficiency, but also causes an increase in environmental pollution (Muazu and Stegemann 2015).

The abundantly available biomass cannot be used for energy production on a large scale due to its low volumetric density, hydrophobicity, lower energy density, and higher moisture contents in comparison to fossil fuels. Due to these characteristics, the cost of handling, transportation, and storage of the raw biomass is relatively high. Moreover, the thermal conversion of raw biomass results in lower energy efficiency during thermal conversion (Ramamurthi et al. 2014; Mostafa et al. 2019; Yang et al. 2019). Over the last decade, different biomass processing technologies have been developed to overcome the energy related issues of raw biomass (Chew and Doshi 2011; Van der Stelt et al. 2011). Biomass solidification molding is one such biomass processing technology in which the biomass is first dried to remove the moisture and then it is crushed. The dried, crushed biomass is rearranged by a mechanical and plastic deformation process at a specific temperature, pressure, and moisture content. The biomass obtained after the solidification and molding is in the form of briquettes or pellets with regular shape, higher density, and higher heating values compared to the raw biomass. The cost of transportation and storage of these pellets is also lower, and the heating value is significantly higher compared to the raw biomass. Moreover, the environmental pollution produced by the burning of the pelleted biomass is also lower due to the higher burning efficiency compared to the raw biomass (Zhou et al. 2016; Pradhan et al. 2018; Mostafa et al. 2019).

The physicochemical properties of the biomass pellets is determined by many factors, including moisture content, particle size, and the chemical properties of the raw material (Kaliyan and Vance Morey 2009). Moreover, the operating conditions of the molding machine, such as holding time, temperature, pressure, and the shape of the die, also affect the quality of the pellets (Larsson et al. 2008; Gilbert et al. 2009; Kaliyan and Vance Morey 2009; Samuelsson et al. 2009; Lestander et al. 2012). Puig-Arnavat et al. (2016) studied the optimum moisture content and temperature for the production of pellets from six different types of biomass using a single particle press; it was concluded that the optimum moisture content for all the materials was $10 \%$. Moreover, the increase of temperature from room temperature to the range 60 to $90{ }^{\circ} \mathrm{C}$ resulted in increased friction. Carone et al. (2011) studied the effect of different process parameters, such as pressure and temperature, as well as the properties of biomass, such as particle size, and the moisture on mechanical properties of the pellets produced from the pruning residue of an olive tree. The results of the study indicated that the temperature is the most influential factor on the mechanical properties, followed by moisture contents of the raw material and pressure. García et al. (2019) studied the effect of moisture and the pelletization temperature on the quality of the pellets produced from pine sawdust. The results of the study showed that the durability and heating value of the pellets was maximum at a moisture content of $16.6 \%$ 
and at a temperature of $80{ }^{\circ} \mathrm{C}$. Tumuluru (2019) studied the effect of the blending ratio of pine and switch grass and their moisture contents on the quality of the pellets. The results of the study showed that lower moisture contents of $20 \%$ (w.b.) and a higher blends ratio of pine resulted in better quality pellets in terms of durability, heating value, and bulk density.

Over the past decade many scientists have studied the effect of different influencing factors on the properties of biomass pellets, but there have been few studies on extractives. The extractives refer to some small molecular weight compounds that can be extracted from biomass by an organic solvent. These compounds include fatty acids, waxes, sterols, terpenes, and so on. When biomass is cut into pieces, these extractive compounds accumulate on the surface to form a chemical layer and prevent the particles from binding. This process is known as passivation, and it is also named weak boundary layer (WBL). The extractives at surfaces can act as a barrier to adhesion (Stehr and Johansson 2000). Therefore, this research has been conducted to study the effect of extractives on the physicochemical properties of pellets produced from the leaves of sycamore trees. The aim of the study is to provide a reference for the production of higher quality molding fuel pellets.

\section{EXPERIMENTAL}

\section{Raw Materials}

The sycamore tree's leaves were collected from Shandong University of Technology (Zibo, China). After collection, the leaves were sun-dried for seven days and then crushed, using a 4-mm sieve mill (Model WN-300A; Xulang Machinery Equipment Co., Ltd., Guangzhou, China). The dried, crushed material was sealed and stored in a wellventilated environment at room temperature $\left(30{ }^{\circ} \mathrm{C}\right)$.

The extracts were then separated from the raw crushed biomass using a Soxhlet extractor (Model SER148-6; VELP, Milan, Italy). The extraction was completed using acetone as an extraction agent for $3 \mathrm{~h}$ as it was done by Nielsen et al. (2010). The extracts obtained from the extraction are shown in Fig. 1.
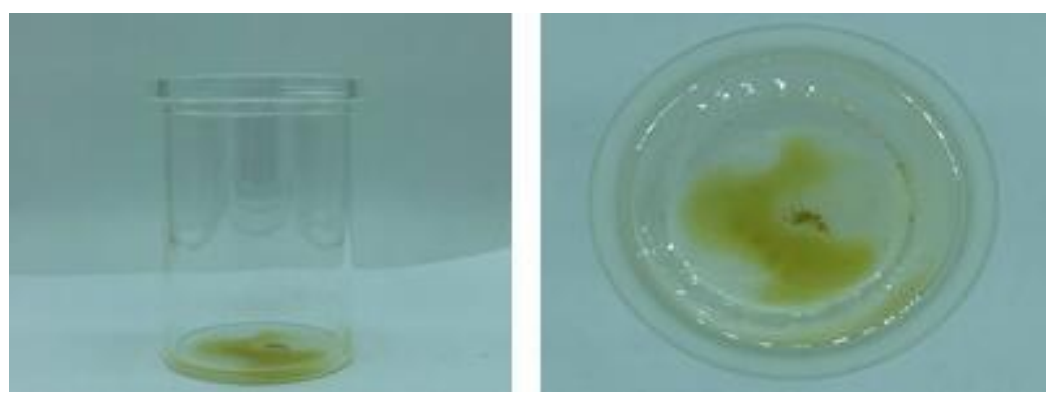

Fig. 1. Extracted results

After extraction, the proximate analysis of the extracted and non-extracted leaves was performed according to Chinese standard GB/T 28731 (2012). Fixed carbon was calculated based on the moisture content, volatile matter, and ash. Elemental analysis was determined with an automatic elemental analyzer (Model Vario EL Cube; Elementar, Frankfurt, Germany). Oxygen content was calculated according to Eq. 1, 


$$
\mathrm{O} \%=1-(\mathrm{C}+\mathrm{H}+\mathrm{N}+\mathrm{S})
$$

where the percentages are based on dry ash free basis. The results of the proximate and elemental analysis are presented in Table 1.

The morphology of the extracted and non-extracted leaves was studied using scanning electron microscopy (SEM) at a magnification of 2000 (Quanta 250; FEI Company, Hillsboro, OR, USA). The SEM images for non-extracted and extracted leaves are presented in Fig. 2(a) and 2(b), respectively.

Table 1. Proximate Analysis and Elemental Analysis of Materials

\begin{tabular}{|c|c|c|}
\hline \multicolumn{1}{|c|}{ Item } & Extracted & Non-extracted \\
\hline \multicolumn{3}{|c|}{ Proximate Analysis (\%) } \\
\hline Moisture & 8.37 & 8.83 \\
\hline Ash & 4.32 & 4.87 \\
\hline Volatile Matter & 64.62 & 63.41 \\
\hline Fixed Carbon & 22.69 \\
\hline \multicolumn{3}{|c|}{ Elemental Analysis (\%) } \\
\hline C & - & 22.89 \\
\hline H & - & 42.59 \\
\hline O & - & 5.68 \\
\hline N & - & 50.42 \\
\hline S & - & 0.98 \\
\hline
\end{tabular}
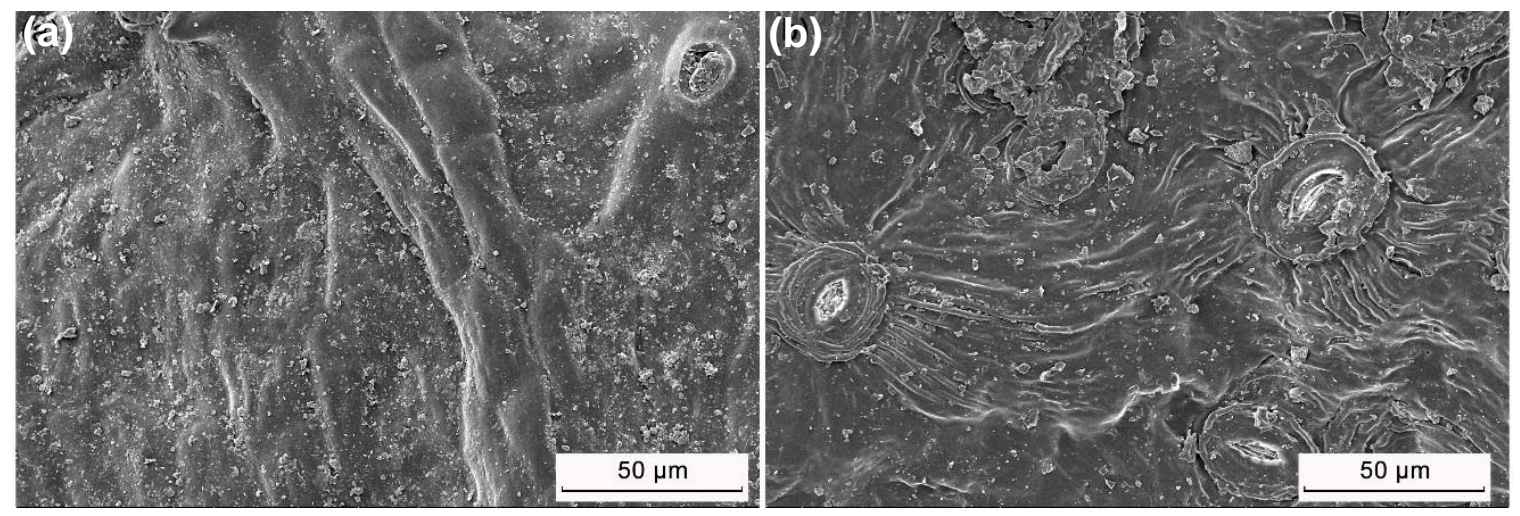

Fig. 2. SEM images of non-extracted (a) and extracted leaves (b)

\section{Methods}

The molding of the extracted and non-extracted leaves was completed using a laboratory molding machine (Model HY-12; Tianguang Optical Instrument Manufacturer, Tianjin, China) with a die diameter of $10 \mathrm{~mm}$ and length of $31 \mathrm{~mm}$.

The initial moisture content of extracted and non-extracted leaves was measured by drying them at $105^{\circ} \mathrm{C}$ until their mass was stabilized (Liu et al. 2013). The initial moisture contents of the extracted and non-extracted leaves were approximately $9 \%$, and then water was added to the extracted and non-extracted leaves to set the moisture at three different levels, i.e., 12, 15, and 18\%. The moisture contents of the extracted and non-extracted leaves were adjusted at higher levels using Eq. 2,

$$
m_{\text {add }}=m_{\text {initial }}\left(K_{2}-K_{1}\right) /\left(1-K_{2}\right)
$$


where $m_{\text {add }}$ is the mass of the water required to adjust the moisture contents at a higher level $(\mathrm{kg}), m_{\text {initial }}$ is the initial mass of raw material $(\mathrm{kg}), K_{1}$ is the initial moisture content of the raw material (\%), and $K_{2}$ is the targeted moisture content of raw material (\%).

After calculating the required mass of the water to be added in the extracted and non-extracted leaves using Eq. 2, the water was mixed homogeneously and then sealed in plastic bags and stored at $4{ }^{\circ} \mathrm{C}$ to avoid any loss of moisture.

After adjustment of the moisture content, the extracted and non-extracted leaves were molded under four different levels of pressure, i.e., 4, 8, 12, and $16 \mathrm{MPa}$. A total of $0.5 \pm 0.01 \mathrm{~g}$ of extracted and non-extracted leaves were used for molding. The biomass was molded using a holding time of $10 \mathrm{~s}$ at room temperature $\left(30^{\circ} \mathrm{C}\right)$. All the treatments of moisture and pressure are presented in Table 2.

Table 2. Experimental Schedule

\begin{tabular}{|c|c|c|c|}
\hline Serial Number & Raw Material & Moisture (\%) & Pressure (MPa) \\
\hline 1 & $\mathrm{NE}$ & $9 \%$ & 4 \\
\hline 2 & NE & $9 \%$ & 8 \\
\hline 3 & $\mathrm{NE}$ & $9 \%$ & 12 \\
\hline 4 & $\mathrm{NE}$ & $9 \%$ & 16 \\
\hline 5 & $\mathrm{NE}$ & $12 \%$ & 4 \\
\hline 6 & $\mathrm{NE}$ & $12 \%$ & 8 \\
\hline 7 & $\mathrm{NE}$ & $12 \%$ & 12 \\
\hline 8 & $\mathrm{NE}$ & $12 \%$ & 16 \\
\hline 9 & NE & $15 \%$ & 4 \\
\hline 10 & NE & $15 \%$ & 8 \\
\hline 11 & $\mathrm{NE}$ & $15 \%$ & 12 \\
\hline 12 & $\mathrm{NE}$ & $15 \%$ & 16 \\
\hline 13 & NE & $18 \%$ & 4 \\
\hline 14 & $\mathrm{NE}$ & $18 \%$ & 8 \\
\hline 15 & $\mathrm{NE}$ & $18 \%$ & 12 \\
\hline 16 & $\mathrm{NE}$ & $18 \%$ & 16 \\
\hline 17 & $E$ & $9 \%$ & 4 \\
\hline 18 & $E$ & $9 \%$ & 8 \\
\hline 19 & $E$ & $9 \%$ & 12 \\
\hline 20 & $E$ & $9 \%$ & 16 \\
\hline 21 & $E$ & $12 \%$ & 4 \\
\hline 22 & $E$ & $12 \%$ & 8 \\
\hline 23 & $E$ & $12 \%$ & 12 \\
\hline 24 & $E$ & $12 \%$ & 16 \\
\hline 25 & $E$ & $15 \%$ & 4 \\
\hline 26 & $E$ & $15 \%$ & 8 \\
\hline 27 & $E$ & $15 \%$ & 12 \\
\hline 28 & $E$ & $15 \%$ & 16 \\
\hline 29 & $E$ & $18 \%$ & 4 \\
\hline 30 & $E$ & $18 \%$ & 8 \\
\hline 31 & $E$ & $18 \%$ & 12 \\
\hline 32 & $E$ & $18 \%$ & 16 \\
\hline
\end{tabular}

Note: NE represents non-extracted leaves and $\mathrm{E}$ represents extracted leaves 
The molding of non-extracted and extracted leaves was performed in triplicates and the average results were used.

\section{Physicochemical characterization}

The physicochemical properties of the pellets were analyzed by measuring their combustion performance, pellet density, and diametric compressive strength.

The combustion performance of the pellets was a concept based on many factors, including ignition temperature, burnout temperature, burning rate, and so on. It was analyzed using a synchronous thermal analyzer (Model STA 449 F5; Netzsch, Selb, Germany). The analysis was started at room temperature $\left(30^{\circ} \mathrm{C}\right)$, the heating rate was 20 ${ }^{\circ} \mathrm{C} / \mathrm{min}$, the flow rate was $20 \mathrm{~mL} \cdot \mathrm{min}^{-1}$, and the termination temperature was $1000{ }^{\circ} \mathrm{C}$ (Cheng et al. 2018).

Immediately after molding, the lengths and diameters of the pellets were measured with a Vernier caliper (accuracy $0.01 \mathrm{~mm}$ ) for further calculation of the volume. The mass was measured with a digital balance (accuracy $0.0001 \mathrm{~g}$ ). Then the pellet density was calculated by the ratio of mass to volume. After measurement, it was stored in a sealed plastic bag for measuring the diametric compressive strength, which was defined as the maximum pressure that pellet can withstand in the radial direction.

The diametric compressive strength was tested using a mechanical testing machine (Model WDW-10G; Tianchen Testing Machine Manufacturing Co., Ltd., Jinan, China). During the test, the upper plate descended at a speed of $10 \mathrm{~mm} / \mathrm{min}$ until the particles broke. The computer automatically recorded the force curve and peak force of the pellets, which was recorded as the diametric compressive strength value of the pellets (Mostafa et al. 2019).

\section{RESULTS AND DISCUSSION}

\section{Analysis of Combustion Performance}

Combustion performance is an important basis for evaluating the chemical properties of biomass pellets. In this study, the combustion performance of biomass pellets was evaluated by the ignition temperature, burnout temperature, and combustion characteristic index by analyzing the thermogravimetric (TG) curve and the derivative thermogravimetric (DTG) curve.

The ignition temperature $\left(T_{\mathrm{i}}\right)$ was determined by the TG-DTG joint definition method. First, a vertical line through the peak point of the DTG curve was made to meet the TG curve. Second, a tangent was made to the intersection (the vertical line of the first step and the TG curve). Finally, the temperature corresponding to the intersection of the tangent and horizontal line when the TG curve begins to lose weight was recorded as the ignition temperature.

The temperature corresponding to the intersection of the tangent (referred to in the previous section) and the horizontal line at the end of the weight loss of the TG curve was recorded as the burnout temperature $\left(T_{\mathrm{f}}\right)$.

The combustion characteristic index $\left(S_{\mathrm{N}}\right)$ is an important indicator for measuring the combustion performance. A larger value results in a better combustion performance. The value of $S_{\mathrm{N}}$ was calculated according to Eq. 3,

$$
S_{\mathrm{N}}=\left(d_{\mathrm{m}} / d_{\mathrm{t}}\right)_{\max }\left(d_{\mathrm{m}} / d_{\mathrm{t}}\right)_{\text {mean }} /\left(T_{\mathrm{i}}^{2} \times T_{\mathrm{f}}\right)
$$


where $\left(d_{\mathrm{m}} / d_{\mathrm{t}}\right)_{\max }$ is the maximum burning rate $(\% / \mathrm{min}),\left(d_{\mathrm{m}} / d_{\mathrm{t}}\right)_{\text {mean }}$ is the average burning rate $(\% / \mathrm{min}), T_{\mathrm{i}}$ is the ignition temperature $\left({ }^{\circ} \mathrm{C}\right)$, and $T_{\mathrm{f}}$ is the burnout temperature $\left({ }^{\circ} \mathrm{C}\right)$.
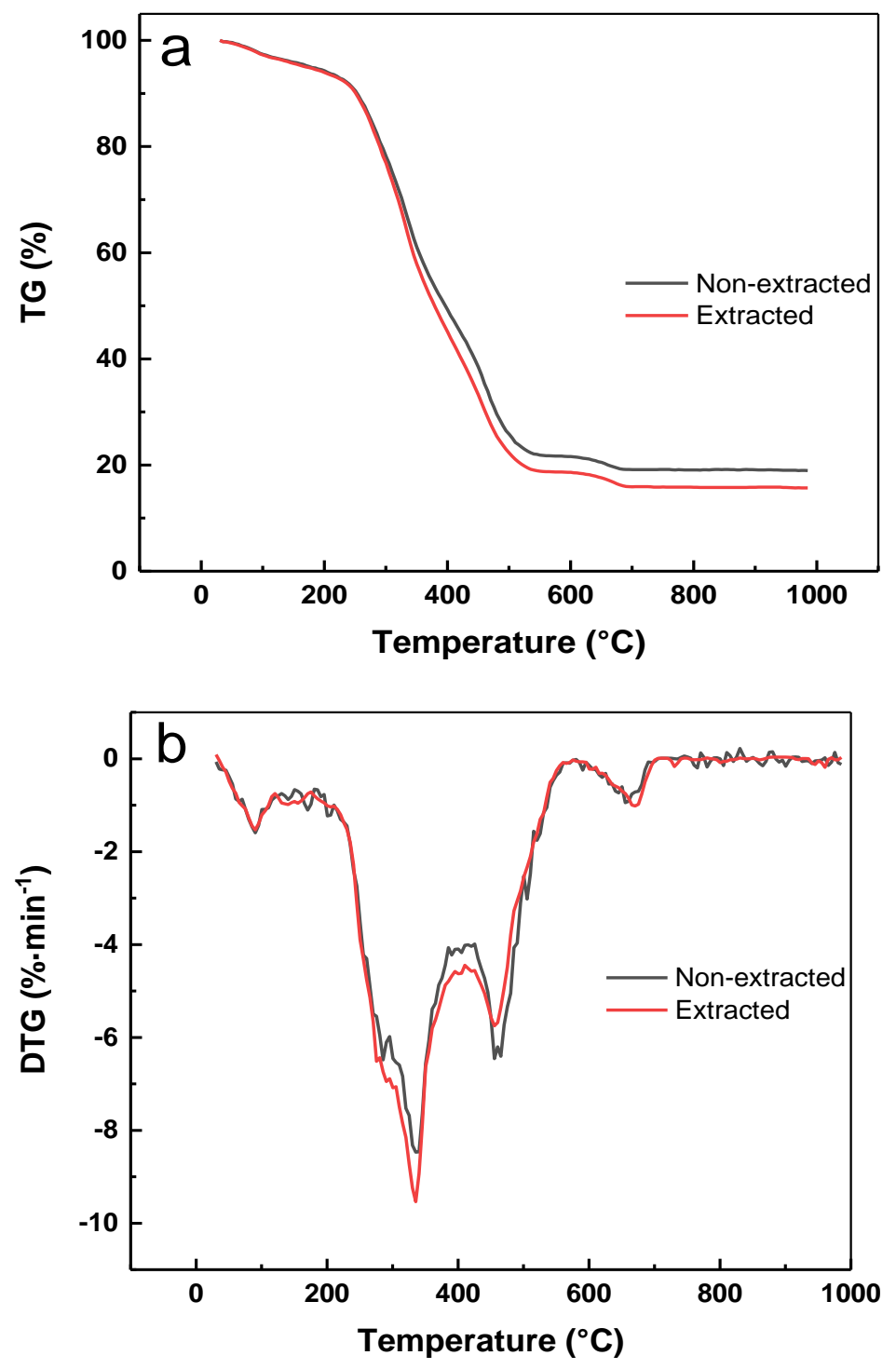

Fig. 3. TG curves (a) and DTG curves (b)

The TG curves and DTG curves are shown in Fig. 3(a) and 3(b), respectively. Both biomass pellets had the same first weight loss peak caused by the removal of moisture at approximately $100{ }^{\circ} \mathrm{C}$. Moreover, the weight loss of moisture in non-extracted leaves' pellets was larger compared to the extracted leaves' pellets, which was consistent with the results displayed in Table 1. With increasing temperature, the combustion of extracted leaves' pellets differed slightly from the non-extracted leaves' pellets. The evaporation of water was followed by the combustion of volatile matter, which occurred in the range $300{ }^{\circ} \mathrm{C}$ to $450{ }^{\circ} \mathrm{C}$. It was observed that the extracted leaves' pellets showed a trend of larger weight loss. In other words, non-extracted leaves' pellets had the highest amount of residue left. The trend of larger weight loss in the extracted leaves' pellet might have been caused by the removal of extractives, which allowed any volatile matter to be easily released. Thus, the extracted leaves' pellets showed a larger second weight loss rate $(9.54 \% / \mathrm{min})$ than non- 
extracted leaves' pellets $(8.47 \% / \mathrm{min})$. This finding was also consistent with the proximate analysis that the volatile content of extracted leaves was higher than that of non-extracted leaves. The results of the study were similar to those of Zhang et al. (2015) who conducted the study on coal gangue. The results also explained the high ash and fixed carbon of nonextracted leaves' pellets presented in Table 1 very well. These results were similar to those obtained by Singh and Zondlo (2017). After that, it was considered to be the combustion of fixed carbon or coke, which was formed by the pyrolysis.

Table 3. Combustion Performance Parameters

\begin{tabular}{|c|c|c|c|c|c|}
\hline $\begin{array}{c}\text { Types of } \\
\text { Pellet }\end{array}$ & $T_{\mathrm{i}}\left({ }^{\circ} \mathrm{C}\right)$ & $T_{\mathrm{f}}\left({ }^{\circ} \mathrm{C}\right)$ & $\begin{array}{c}\left(d_{\mathrm{m}} / d_{\mathrm{t}}\right)_{\max } \\
\left(\% \cdot \mathrm{min}^{-1}\right)\end{array}$ & $\begin{array}{c}\left(d_{\mathrm{m}} / d_{\mathrm{t}}\right)_{\operatorname{mean}} \\
\left(\% \cdot \mathrm{min}^{-1}\right)\end{array}$ & $\begin{array}{c}S_{\mathrm{N}} \\
\left(10^{-6} \mathrm{~min}^{-2} \mathrm{~K}^{-3}\right)\end{array}$ \\
\hline Extracted & 245.8 & 445.8 & 9.54 & 5.70 & 2.02 \\
\hline $\begin{array}{c}\text { Non- } \\
\text { extracted }\end{array}$ & 250.4 & 460.4 & 8.47 & 5.26 & 1.54 \\
\hline
\end{tabular}

The combustion performance parameters of the extracted and non-extracted leaves' pellets obtained by the TG and DTG curves are presented in Table 3. There was considerable difference in these parameters between the extracted and non-extracted leaves' pellets. As shown in Table 3, extracted leaves' pellets exhibited lower ignition and burnout temperature; in other words, extracted leaf pellets are easy to ignite and burn out (Zhang et al. 2015). By comparing the maximum burning rate, the average burning rate, and the combustion characteristic index, extracted leaf pellets had a higher value than that of non-extracted. Thus, the combustion performance of extracted leaves' pellets was much better than that of non-extracted.

In summary, the combustion performance of extracted leaves' pellets was remarkably different from the non-extracted leaves' pellets. The difference in combustion performance was mainly due to the removal of extractives, resulting in complete release of biomass components during burning. Therefore, the extracted leaves' pellets were easier to ignite, burned faster, and burned more completely than non-extracted leaves' pellets. Overall, extraction can help to improve the combustion performance.

\section{Physical Performance Analysis}

Pellet density is an important parameter that determines the cost of transportation and storage, as well as the efficiency of utilization. Figure 4 shows the pellet density of extracted and non-extracted leaf pellets at different moisture and pressure levels. It is clear from Fig. 4 that pellet density for extracted and non-extracted leaf pellets was in the range of 1000 to approximately $1250 \mathrm{~kg} / \mathrm{m}^{3}$. These values are comparable with the results found by Said et al. (2015). It was also clear from Fig. 4 that extracted leaf pellets had a higher pellet density than those that were non-extracted, which might have been due to the removal of extractives after the extracts. The extracted leaf pellets showed higher pellet density because the removal of extractives resulted in better bonding of the particles due to the increase of bonding area; therefore, the pellet density of the particles was increased (Bergstrom et al. 2010; Nielsen et al. 2010). Furthermore, the SEM images showed that 
the morphology of extracted leaves was rougher when compared to non-extracted. In other words, extractives might prevent particles from bonding.

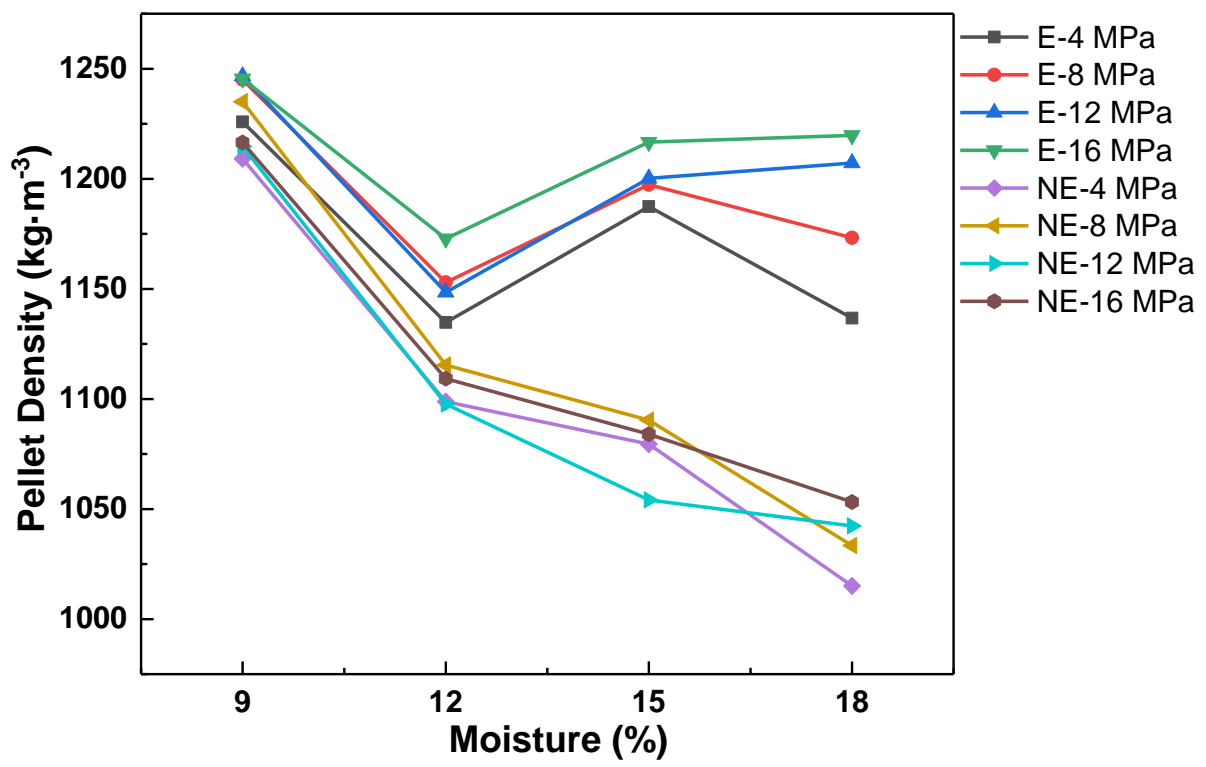

Fig. 4. Pellet density of extracted and non-extracted leaves pellets

In the process of biomass molding, moisture acts as both a binder and lubricant (Kaliyan and Vance Morey 2009; Huang et al. 2017). When the moisture contents of the biomass are higher, water will surround the particles and affect the bonding. Moreover, the friction between the biomass molecules will increase with the increase of moisture content, resulting in the inability of the particles to be tightly bound (Bergstrom et al. 2010; Nielsen et al. 2010). The optimum moisture contents for both extracted and non-extracted leaves' pellets was 9\%, which was consistent with the study by Puig-Arnavat et al. (2016). The pellet density of non-extracted leaves' pellets decreased as the moisture content increased, while extracted leaves' pellets achieved a second peak value at $15 \%$ moisture content, which was lower than the first peak value at $12 \%$ moisture content. The maximum pellet density was observed at moisture content of $9 \%$ for both the leaves because water occupies the space between the particles, so the mass increases but the volume does not change, resulting in a maximum of pellet density (Huang et al. 2017). With the increase of moisture level in the extracted leaves, the extra water occupies the volume and sticks on the surface of the particle; furthermore, the biomass particles cannot bind well, resulting in a decrease of density. In contrast, in the non-extracted leaves' pellets, the extra water at higher moisture contents attached to the particle due to the presence of extractives, which prevents water from entering the space (Nielsen et al. 2010). Due to this reason, the pellet density of non-extracted leaves decreased with the increase of moisture content, as shown in Fig. 4. As for the two peak values of extracted leaves' pellets, it could have been because (1) At moisture contents of $9 \%$ to $12 \%$, the friction between particles increased due to the absence of extractives, then water, which acts as a lubricant, cannot eliminate the effect of friction. As a result, particles cannot bond well, and thus the pellet density decreases. (2) At a moisture level of $12 \%$ to $15 \%$, the friction between the particles was greatly reduced with the increase of moisture, and the binding of the particles also increased, resulting in the increase of the pellet density. (3) At a moisture level higher than 15\%, the extra 
moisture prevented the particles from bonding by sticking on the particles, which caused the density to decrease. The results of the study were found comparable with that of Nielsen et al. (2010).

The pellet density of the biomass pellet is also affected by pressure. Figure 4 shows that the pellet density increased with the increase of pressure. This was attributed to the removal of extractives that allowed biomass particles to expose more binding sites, resulting in better bonding (Nielsen et al. 2010). Therefore, a higher pressure resulted in more bonding surface, which caused the particle to be compacted. For constant quality, it has a smaller volume, which causes an increase in pellet density. It also can be interpreted that the extractives that are present act as a lubricant. Once they are removed, the particles can contact each other directly. This increases the friction so that a higher pressure is required.

In summary, extraction can better lead to an increase in the density of the biomass pellets. Moisture content and pressure affected the pellet density of the biomass pellets. Beyond the optimum moisture content, the pellet density of the biomass pellets will decrease with the increase of moisture content. The molding pressure is positively correlated with the pellet density, and a higher molding pressure will result in a higher pellet density.

\section{Diametric Compressive Strength}

Figure 5 shows the diametric compressive strength of the extracted and nonextracted leaves' pellets.
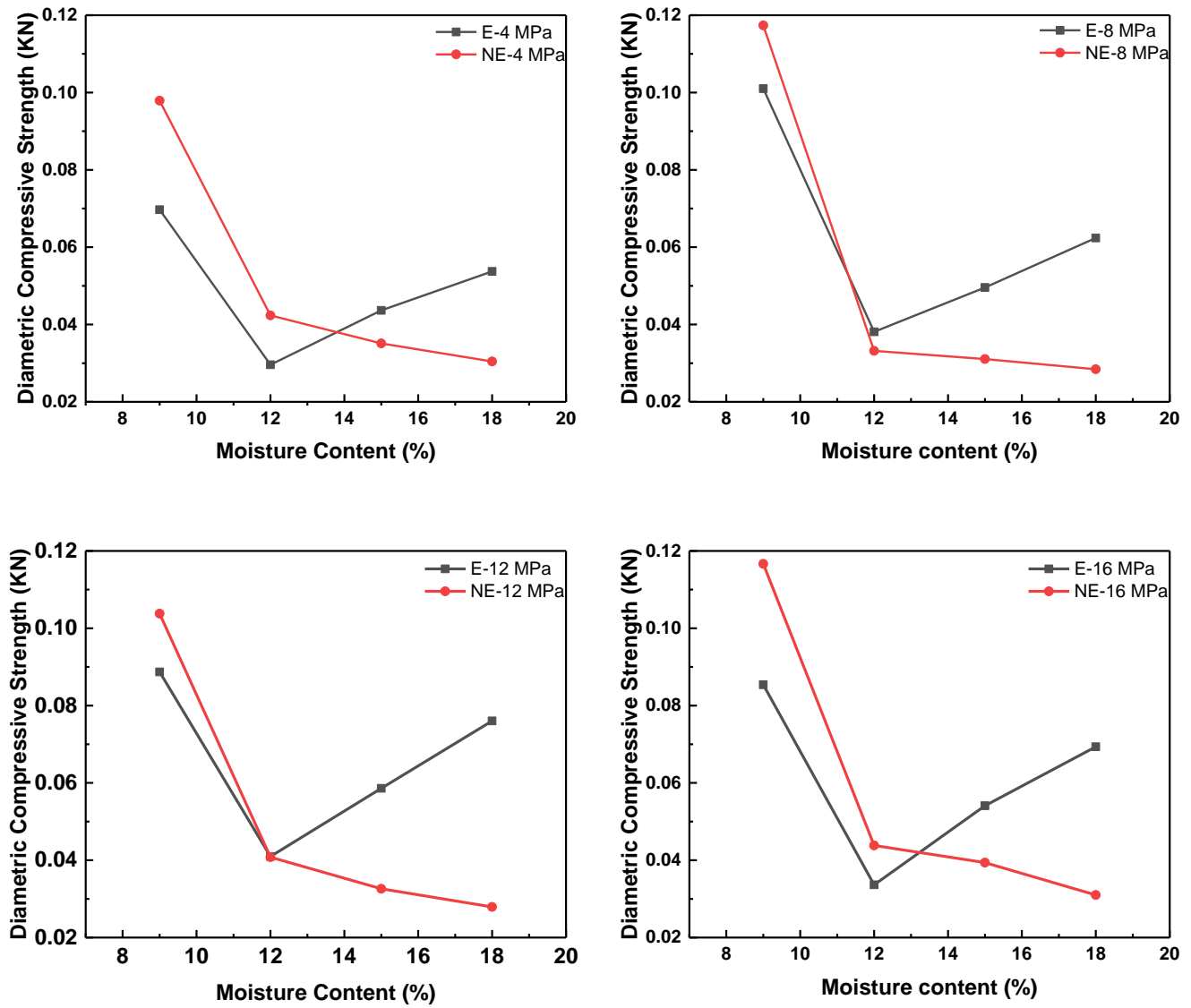

Fig. 5. Diametric compressive strength of extracted and non-extracted leaves' pellets 
As shown in Fig. 5, there was not always a better performance in extracted leaves' pellets when compared to non-extracted. It can be seen from Fig. 5 that for non-extracted leaves' pellets, the maximum value of the diametric compressive strength occurred at a moisture content of approximately $9 \%$. Then, it decreased with the increase of the moisture content, which might explain the weak capacity of "water-lock" of non-extracted leaves. The result also was consistent with the conclusion of the effect of moisture content on pellet density. This might explain, from some aspect, that the pellet density has a positive correlation with diametric compressive strength: a higher pellet density resulted in a larger the diametric compressive strength. For extracted leaves' pellets, the diametric compressive strength increased when the moisture was beyond approximately $12 \%$. For that reason, it might be due to the higher capacity of "water-lock" of extracted leaves. This may have been because the moisture was wrapped around the particles, and water is incompressible, thus increasing the diametric compressive strength.

\section{CONCLUSIONS}

1. Extractives can act as a blocking layer at the surfaces of pieces of biomass. Removal of extractives had a clear promotional impact on the physicochemical properties of biomass pellets.

2. Moisture and pressure had a positive effect on the physicochemical properties of biomass pellets. Once beyond the optimum value, both moisture and pressure will have a negative effect.

3. No obvious evidence showed the removal of extractives can increase diametric compression strength.

\section{REFERENCES CITED}

Bajwa, D. S., Peterson, T., Sharma, N., Shojaeiarani, J., and Bajwa, S. G. (2018). "A review of densified solid biomass for energy production," Renewable and Sustainable Energy Reviews 96, 296-305. DOI: 10.1016/j.rser.2018.07.040

Bergstrom, D., Finell, M., Gref, R., and Sveriges, L. (2010). "Effects of extractives on the physical characteristics of scots pine sawdust fuel pellets," Forest Products Journal 60(7-8), 640-644. DOI: 10.13073/0015-7473-60.7.640

Carone, M. T., Pantaleo, A., and Pellerano, A. (2011). "Influence of process parameters and biomass characteristics on the durability of pellets from the pruning residues of Olea europaea L.," Biomass and Bioenergy 35(1), 402-410.

DOI: 10.1016/j.biombioe.2010.08.052

Cheng, J., Zhou, F., Si, T., Zhou, J., and Cen, K. (2018). "Mechanical strength and combustion properties of biomass pellets prepared with coal tar residue as a binder," Fuel Processing Technology 179, 229-237. DOI: 10.1016/j.fuproc.2018.07.011

Chew, J. J., and Doshi, V. (2011). "Recent advances in biomass pretreatmentTorrefaction fundamentals and technology," Renewable and Sustainable Energy Reviews 15(8), 4212-4222. DOI: 10.1016/j.rser.2011.09.017 
García, R., Gil, M. V., Rubiera, F., and Pevida, C. (2019). "Pelletization of wood and alternative residual biomass blends for producing industrial quality pellets," Fuel 251, 739-753. DOI: 10.1016/j.fuel.2019.03.141

GB/T 28731 (2012). "Proximate analysis of solid biofuels," Standardization Administration of China, Beijing, China.

Gilbert, P., Ryu, C., Sharifi, V., and Swithenbank, J. (2009). "Effect of process parameters on pelletisation of herbaceous crops," Fuel 88(8), 1491-1497. DOI: 10.1016/j.fuel.2009.03.015

Huang, Y., Finell, M., Larsson, S., Wang, X., Zhang, J., Wei, R., and Liu, L. (2017). "Biofuel pellets made at low moisture content-Influence of water in the binding mechanism of densified biomass," Biomass and Bioenergy 98, 8-14. DOI: 10.1016/j.biombioe.2017.01.002

Kaliyan, N., and Vance Morey, R. (2009). "Factors affecting strength and durability of densified biomass products," Biomass and Bioenergy 33(3), 337-359.

DOI: 10.1016/j.biombioe.2008.08.005.

Larsson, S. H., Thyrel, M., Geladi, P., and Lestander, T. A. (2008). "High quality biofuel pellet production from pre-compacted low density raw materials," Bioresource Technology 99(15), 7176-7182. DOI: 10.1016/j.biortech.2007.12.065

Lestander, T. A., Finell, M., Samuelsson, R., Arshadi, M., and Thyrel, M. (2012). "Industrial scale biofuel pellet production from blends of unbarked softwood and hardwood stems-the effects of raw material composition and moisture content on pellet quality," Fuel Processing Technology 95, 73-77. DOI: 10.1016/j.fuproc.2011.11.024

Liu, Z., Liu, X., Fei, B., Jiang, Z., Cai, Z., and Yu, Y. (2013). "The properties of pellets from mixing bamboo and rice straw," Renewable Energy 55, 1-5. DOI: 10.1016/j.renene.2012.12.014

McKendry, P. (2002). "Energy production from biomass (Part 1): Overview of biomass," Bioresource Technology 83(1), 37-46. DOI: 10.1016/S0960-8524(01)00118-3

Muazu, R. I., and Stegemann, J. A. (2015). "Effects of operating variables on durability of fuel briquettes from rice husks and corn cobs," Fuel Processing Technology 133, 137-145. DOI: 10.1016/j.fuproc.2015.01.022

Mostafa, M. E., Hu, S., Wang, Y., Su, S., Hu, X., Elsayed, S. A., and Xiang, J. (2019). "The significance of pelletization operating conditions: An analysis of physical and mechanical characteristics as well as energy consumption of biomass pellets," Renewable and Sustainable Energy Reviews 105, 332-348. DOI: 10.1016/j.rser.2019.01.053

Nielsen, N. P. K., Gardner, D. J., and Felby, C. (2010). "Effect of extractives and storage on the pelletizing process of sawdust," Fuel 89(1), 94-98. DOI: 10.1016/j.fuel.2009.06.025

Pradhan, P., Mahajani, S. M., and Arora, A. (2018). "Production and utilization of fuel pellets from biomass: A review," Fuel Processing Technology 181, 215-232. DOI: 10.1016/j.fuproc.2018.09.021

Puig-Arnavat, M., Shang, L., Sárossy, Z., Ahrenfeldt, J., and Henriksen, U. B. (2016). "From a single pellet press to a bench scale pellet mill - Pelletizing six different biomass feedstocks," Fuel Processing Technology 142, 27-33. DOI:

10.1016/j.fuproc.2015.09.022 
Ramamurthi, P. V., Fernandes, M. C., Nielsen, P. S., and Nunes, C. P. (2014). "Logistics cost analysis of rice residues for second generation bioenergy production in Ghana," Bioresource Technology 173, 429-438. DOI: 10.1016/j.biortech.2014.09.102

Samuelsson, R., Thyrel, M., Sjöström, M., and Lestander, T. A. (2009). "Effect of biomaterial characteristics on pelletizing properties and biofuel pellet quality," Fuel Processing Technology 90(9), 1129-1134. DOI: 10.1016/j.fuproc.2009.05.007

Said, N., Abdel Daiem, M. M., García-Maraver, A., and Zamorano, M. (2015). "Influence of densification parameters on quality properties of rice straw pellets," Fuel Processing Technology 138, 56-64. DOI: 10.1016/j.fuproc.2015.05.011

Saidur, R., Abdelaziz, E. A., Demirbas, A., Hossain, M. S., and Mekhilef, S. (2011). "A review on biomass as a fuel for boilers," Renewable and Sustainable Energy Reviews 15(5), 2262-2289. DOI: 10.1016/j.rser.2011.02.015

Singh, K., and Zondlo, J. (2017). "Characterization of fuel properties for coal and torrefied biomass mixtures," Journal of the Energy Institute 90(4), 505-512. DOI: 10.1016/j.joei.2016.05.012

Stehr, M., and Johansson, I. (2000). "Weak boundary layers on wood surfaces," Journal of the Adhesion Science and Technology 14(10), 1211-1224. DOI: $10.1163 / 156856100742168$

Tumuluru, J. (2019). "Pelleting of pine and switchgrass blends: Effect of process variables and blend ratio on the pellet quality and energy consumption," Energies 12(7), Article ID 1198. DOI: 10.3390/en12071198

Van der Stelt, M. J .C., Gerhauser, H., Kiel, J. H. A., and Ptasinski, K. J. (2011). "Biomass upgrading by torrefaction for the production of biofuels: A review," Biomass and Bioenergy 35(9), 3748-3762. DOI: 10.1016/j.biombioe.2011.06.023

Yang, Y., Sun, M., Zhang, M., Zhang, K., Wang, D., and Lei, C. (2019). "A fundamental research on synchronized torrefaction and pelleting of biomass," Renewable Energy 142, 668-676. DOI: 10.1016/j.renene.2019.04.112

Zhang, Y., Guo, Y., Cheng, F., Yan, K., and Cao, Y. (2015). "Investigation of combustion characteristics and kinetics of coal gangue with different feedstock properties by thermogravimetric analysis," Thermochimica Acta 614, 137-148. DOI: $10.1016 /$ j.tca.2015.06.018

Zhou, Y., Zhang, Z., Zhang, Y., Wang, Y., Yu, Y., Ji, F., Ahmad, R., and Dong, R. (2016). "A comprehensive review on densified solid biofuel industry in China," Renewable and Sustainable Energy Reviews 54, 1412-1428. DOI:

10.1016/j.rser.2015.09.096

Article submitted: September 10, 2019; Peer review completed: November 19, 2019; Revised version received: November 25, 2019; Accepted: December 1, 2019; Published: December 3, 2019.

DOI: 10.15376/biores.15.1.544-556 